\title{
Obstructive Azoospermia in a Patient with VATER Association
}

\author{
Zhanyong Bing \\ Department of Pathology and Laboratory Medicine, Hospital of the University of Pennsylvania, Philadelphia, USA. \\ Email: bingz@uphs.upenn.edu
}

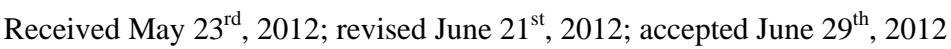

\begin{abstract}
VATER association was first described in 1968 by Say and Gerald and is an association of congenital anomalies including $V$ (vertebral defect), $A$ (anal atresia), $T E$ (tracheoesophegeal fistula), and $R$ (radial dysplasia and renal defects). This report described a 26 year-old man with VATER association presented with infertility. Hormone tests including follicular stimulating hormone, luteinizing hormone and testosterone were normal. Semen analysis showed azoospermia. A testicular biopsy was performed and showed the presence of all of germinative components, germ cell sloughing, and mild hypospermatogenesis. The findings were compatible with obstructive azoospermia. No evidence of intratubular germ cell neoplasia unclassified was identified.
\end{abstract}

Keywords: VATER Association; Obstructive; Azoospermia

\section{Introduction}

Infertility can be attributed to men in $30 \%-40 \%$ of infertile couples, which may be due to endocrine disruption of gonadal development during early pregnancy, environment pollution and genetic factors. Azoospermia can be secondary to obstructive or non-obstructive etiologies. Testicular biopsy plays a definitive role in confirming the obstructive azoospermia, which in turn leads to appropriate management.

VATER association was first described in 1968 by Say and Gerald [1] and is an association of congenital anomalies including $V$ ( vertebral defect), A (anal atresia), $T E$ (tracheoesophegeal fistula), and $R$ (radial dysplasia and renal defects) [2,3]. Since the introduction of the acronym, various expansions in an effort to further define the scope of the VATER association have been suggested, such as $V$ in VATER was expanded to include vascular anomalies [4]. It has been suggested to expand the acronym to VACTERL with the $C$ denoting cardiovascular anomalies and the $L$ denoting limb anomalies [5]. About half of the patients with VATER association also show the urologic anomalies [6,7]. No obstructive azoospermia has been reported in the patients with VATER association. In this report a men with VATER association with an obstructive azoospermia was described.

\section{Clinical History}

The patient was a 26 year old man who was born with an imperforate anus and hypospadias. He had one functional kidney. He had a colostomy from 1986 to 1997 and then was reversed. He had fecal incontinence. Colorectal evaluation showed minimal tone and no appreciable functional sphincter. He developed hydrocele in 2005 and it was enlarged since then. He had no issues with erection or orgasm. In 2009 he had a semen analysis that showed azoospermia. Hormone tests were done in 2011 and showed that follicular stimulating hormone, luteinizing hormone and total testosterone were within normal limits. He reported occasional dysuria and had to strain to void at times. He had in intermittent stream. He denied hematuria or urolithiasis. A testicular biopsy and resection of hydrocele sac was performed.

\section{Pathology}

The testicular biopsy showed the presence of all germinative elements (Figures 1(a) and (b)). The majority of the tubules showed sloughing of the immature germinative elements. The modal Johnsen score was 9. The mean spermatid count per tubules was 10 . The tubular basement membranes showed mild thickening. No Leydig cell hyperplasia was seen. The vessels were unremarkable. No morphological evidence for intratubular germ cell neoplasia unspecificed was identified. Immunohistochemical stains for OCT3/4 and PLAP were performed and were negative.

\section{Discussion}

VATER association describes a non-random group of 


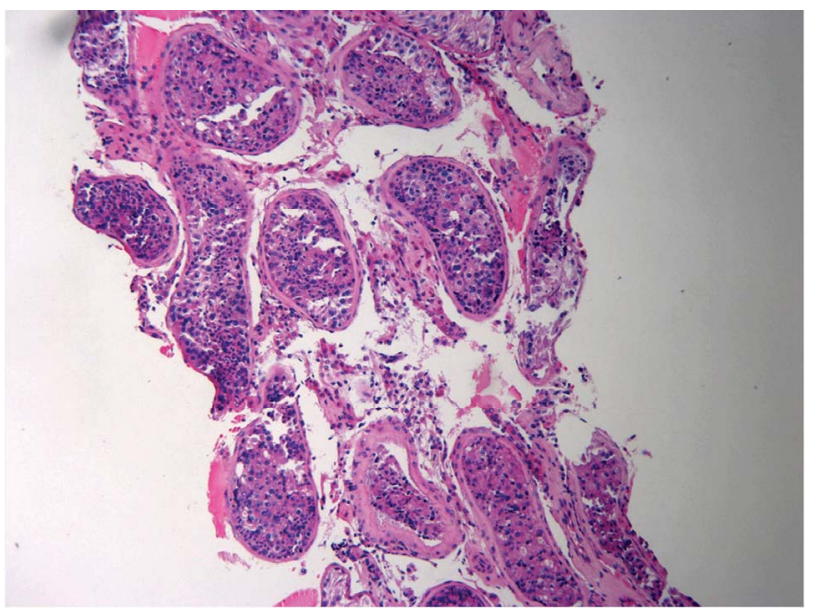

(a)

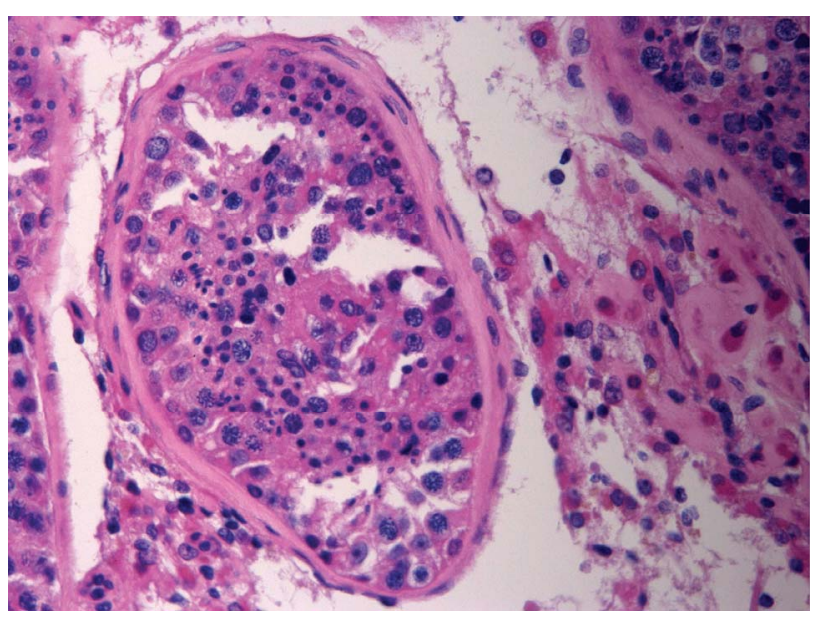

(b)

Figure 1. Testicular biopsy in a patient with VATER association. (a) Germ cell sloughing; (b) All of germinative components were present.

vertebral, anal, radial and renal malformations. The incidence ranges from 0.03 to $1.6 / 10,000$ live birth $[5,8]$. The underlying molecular mechanisms are yet to be determined. Chromosome studies done in 19 of the infants were reported normal [9]. Population based study suggests an association between maternal diabetes and multisystem anomalies. Incidence of VATER association in infants of diabetic mothers was five times higher that that of babies of nondiabetic mothers [10]. Interestingly, it has been shown that a novel germ line mutation of the PTEN gene in a patient with macrocephaly, ventricular dilatation and features of VATER association [11].

Reported anomalies of VATER association in the genitourinary tract include the malformation of male external genitalia [12], vaginal membranous septum [13], and agenesis of the fallopian tubes, uterus, and vagina [14]. Obstructive azoospermia in VATER association has not been reported.

Obstructive azoospermia can be confirmed by testicu- lar biopsy, which is usually performed for the following reasons. First is to confirm the obstructive nature of azoospermia, which may provide guidance for future management, including surgical correction if appropriate. Second is for sperm harvesting for in vitro fertilization. In this scenario, a testicular biopsy is needed to estimate the success rate for future sperm harvesting, and at same time to diagnose intratubular germ cell neoplasia unclassified (ITGCNU). Infertility, like other risk factors, such as a history of cryptorchidism and testicular germ cell tumor and gonadal digenesis has a higher chance for ITGCNU [15].

As this patient was normal for hormone tests and semen analysis showed azoospermia. A testicular biopsy was performed. In the biopsy, all germinative elements were present. There were germ cell sloughing and mild hypospermatogenesis. This report suggested that patients with VATER association could present with azoospermia. Testicular biopsy may be a useful tool to confirm the obstructive nature of azoospermia. No morphological or immunohistochemical evidences for ITGCNU were identified in this case.

\section{REFERENCES}

[1] B. Say and P. S. Gerald, "A New Polydactyly/Imperforate-Anus/Vertebral-Anomalies Syndrome?” Lancet, Vol. 2, No. 7569, 1968, p. 688. doi:10.1016/S0140-6736(68)92549-X

[2] A. H. Nora and J. J. Nora, “A Syndrome of Multiple Congenital Anomalies Associated with Teratogenic Exposure,” Archives of Environmental Health, Vol. 30, No. 1, 1975, pp. 17-21.

[3] J. M. Spoon, "VATER Association," Neonatal Network, Vol. 22, No. 3, 2003, pp. 71-75. doi:10.1891/0730-0832.22.3.71

[4] S. A. Temtamy and J. D. Miller, "Extending the Scope of the VATER Association: Definition of the VATER Syndrome," Journal of Pediatrics, Vol. 85, No. 3, 1974, pp. 345-349. doi:10.1016/S0022-3476(74)80113-7

[5] M. J. Khoury, J. F. Cordero, F. Greenberg, L. M. James and J. D. Erickson, "A Population Study of the VACTERL Association: Evidence for Its Etiologic Heterogeneity,” Pediatrics, Vol. 71, No. 5, 1983, pp. 815-820.

[6] L. Quan and D. W. Smith, "The VATER Association. Vertebral Defects, Anal Atresia, T-E Fistula with Esophageal Atresia, Radial and Renal Dysplasia: A Spectrum of Associated Defects," Journal of Pediatrics, Vol. 82, No. 1, 1973, pp. 104-107. doi:10.1016/S0022-3476(73)80024-1

[7] D. T. Uehling, E. Gilbert and R. Chesney, "Urologic Implications of the VATER Association,” Journal of Urology, Vol. 129, No. 2, 1983, pp. 352-354.

[8] L. D. Botto, M. J. Khoury, P. Mastroiacovo, E. E. Castilla, C. A. Moore, R. Skjaerven, O. M. Mutchinick, B. Borman, G. Cocchi, A. E. Czeizel, et al., "The Spectrum of 
Congenital Anomalies of the VATER Association: An International Study," American Journal of Medical Genetics, Vol. 71, No. 1, 1997, pp. 8-15.

doi:10.1002/(SICI)1096-8628(19970711)71:1<8::AID-AJ MG2>3.0.CO;2-V

[9] D. D. Weaver, C. L. Mapstone and P. L. Yu, "The VATER Association. Analysis of 46 Patients,” American Journal of Diseases of Children, Vol. 140, No. 3, 1986, pp. 225-229.

[10] M. J. Bull, C. Q. Bryson, J. Grosfeld and R. L. Schreiner, "VATER Association: Analysis of Growth and Development," American Journal of Perinatology, Vol. 2, No. 1, 1985, pp. 35-38. doi:10.1055/s-2007-999908

[11] W. Reardon, X. P. Zhou and C. Eng, "A Novel Germline Mutation of the PTEN Gene in a Patient with Macrocephaly, Ventricular Dilatation, and Features of VATER Association,” Journal of Medical Genetics, Vol. 38, No. 12, 2001, pp. 820-823. doi:10.1136/jmg.38.12.820
[12] J. Apold, E. Dahl and D. Aarskog, “The Vater Association: Malformations of the Male External Genitalia,” Acta Paediatrica Scandinavica, Vol. 65, No. 2, 1976, pp. 150152. doi:10.1111/j.1651-2227.1976.tb16528.x

[13] B. Say, N. J. Carpenter and E. I. Smith, "Genital Malformations in a Child with VATER Association," American Journal of Diseases of Children, Vol. 133, No. 4, 1979, pp. 438-439.

[14] S. L. King, R. L. Ladda and S. J. Shochat, "Monozygotic Twins Concordant for Tracheo-Esophageal Fistula and Discordant for the VATER Association," Acta Paediatrica Scandinavica, Vol. 66, No. 6, 1977, pp. 783-785. doi:10.1111/j.1651-2227.1977.tb07989.x

[15] G. R. Dohle, S. Elzanaty and N. J. van Casteren, "Testicular Biopsy: Clinical Practice and Interpretation,” Asian Journal of Andrology, Vol. 14, No. 1, 2012, pp. 88-93. doi:10.1038/aja.2011.57 